Industrial Health, 1976, 14, 75.

\title{
FLUOROMETRIC MICROMEASUREMENT OF DELTA- AMINOLEVULINIC ACID DEHYDRATASE ACTIVITY IN HUMAN ERYTHROCYTES AS AN INDEX OF LEAD EXPOSURE
}

\author{
Katsumaro TOMOKUNI \\ Department of Public Health, Okayama University Medical School, \\ Shikata-Machi, Okayama
}

(Received September 4, 1976)

\begin{abstract}
I describe a fluorometric micromethod for determining delta-aminolevulinic acid dehydratase (ALA-D) activity in whole blood. In this method, the porphobilinogen formed under the incubation condition using $0.05 \mathrm{~m} l$ of whole blood is easily converted to uroporphyrin by heating for $15 \mathrm{~min}$ at $100^{\circ} \mathrm{C}$ in an acidic medium in the presence of air. The uroporphyrin formed is a stable and highly fluorescent substance and its fluorescence intensity is measured using a spectrofluorophotometer.

The ALA-D activity is expressed as nanomoles of uroporphyrin formed per hour per milliliter of erythrocytes. This method offers some advantages that it is much sensitive and is employed without Ehrlich's reagent.

The erythrocyte ALA-D activity measured by the fluorometric method has a good correlation with that measured by the colorimetric method with Ehrlich's reagent $(r=0.9484)$.
\end{abstract}

Delta-aminolevulinic acid dehydratase (ALA-D), which catalyses the synthesis of porphobilinogen from two molecules of delta-aminolevulinic acid (ALA), is largely contained in circulating erythrocytes. This enzyme is extremely sensitive to inhibition by inorganic lead. It has been demonstrated that the erythrocyte ALA-D activity is inversely correlated to the concentration of lead in blood ${ }^{1 \sim 4)}$.

Therefore, the determination of erythrocyte ALA-D activity is a practical screening test for detecting the degree of the biological effects by lead in workers occupationally exposed to lead.

Routinely, the ALA-D activity is usually measured according to the colorimetric method of Bonsignore, et al. ${ }^{5)}$ or its modifications ${ }^{2,6}{ }^{(8)}$, a method based on the original assays described by Gibson, et al.9) and Granick and Mauzerall ${ }^{10)}$. In these procedures, the amount of porphobilinogen formed during incubation is spectrophotometrically determined after a color reaction with Ehrlich's reagent. On the other hand, I1) reported a 


\section{K. TOMOKUNI}

method based on the colorimetric determination of the substrate ALA consumed by the enzyme assay. However, in all the colorimetric methods for ALA-D determination has been described above, it is essential to use the Ehrlich's reagent. The use of the Ehrlich's reagent which is prepared from p-dimethylaminobenzaldehyde, glacial acetic acid and perchloric acid reagents has some disadvantages; This reagent is irritative for the skin and then the discard of the reagent after the use may cause water pollution.

More recently, Chakrabarti, et al. ${ }^{22)}$ introduced a fluorometric method for determination of erythrocyte ALA-D activity with no use of Ehrlich's reagent. In their method, the enzyme assay was done according to the procedure described by Burch and Siegel ${ }^{7}$, in which $0.2 \mathrm{ml}$ of whole blood was used, and the porphobilinogen formed during incubation was converted to a stable and highly fluorescent uroporphyrin by heating. On the other hand, the author tried a fluorometric microdetermination after performing the enzyme assay by the slight modification of Weissberg, et al. ${ }^{2}$ ) method, in which $0.05 \mathrm{~m} l$ of whole blood was used. This result will be describe in the present paper.

\section{Materials AND Methods}

\section{Blood specimens}

Whole bloods were collected from 60 mens of the outpatients who visited the Okayama University Hospital. After measuring hematocrits with a microcapillary centrifuge, the blood samples were stored in an ice bath at 1 to $2^{\circ} \mathrm{C}$ until the ALA-D activity was measured.

\section{Reagents}

(a) Sodium phosphate buffer, $0.2 \mathrm{~mol} / \mathrm{liter}, \mathrm{pH} 6.8$. (b) ALA aqueous solution, $20 \mathrm{mmol} /$ liter. (c) Trichloroacetic acid (TCA) for colorimetry $(100 \mathrm{~g} /$ liter TCA containing $0.1 \mathrm{~mol} /$ liter $\mathrm{HgCl}_{2}$ ). (d) Trichloroacetic acid (TCA) for fluorometry, $100 \mathrm{~g} /$ liter. (e) Ehrlich's reagent (2 $\mathrm{g}$ of $\mathrm{p}$-dimethylaminobenzaldehyde dissolved in $60 \mathrm{ml}$ of glacial acetic acid, with $32 \mathrm{ml}$ of $70 \%$ perchloric acid added, and the total volume adjusted to $100 \mathrm{~m} l$ with glacial acetic acid). (f) Coproporphyrin standard, $0.1 \mu \mathrm{g} / \mathrm{ml}$ (This solution was prepared from a preweighed vial containing $5 \mu \mathrm{g}$ of coproporphyrin I (Sigma). After adding $10 \mathrm{ml}$ of $1.5 \mathrm{~N} \mathrm{HCl}$ to the vial, it was warmed for $3 \mathrm{~min}$ in a boiling water bath. The solution $1 \mathrm{~m} l$ was diluted to $5 \mathrm{~m} l$ with $1.5 \mathrm{~N} \mathrm{HCl}$ ).

\section{Colorimetric method}

The enzyme assay was performed according to the slight modification of Bonsignore, et al. ${ }^{5)}$ method. To $1.3 \mathrm{ml}$ of distilled water, add $0.2 \mathrm{ml}$ of whole blood in two test tubes (sample and blank) and mix well to assure complete hemolysis of the erythrocytes. Then, to the test tubes add $0.5 \mathrm{ml}$ of phosphate buffer and place it in a constant-temperature water bath at $37^{\circ} \mathrm{C}$ for $5 \mathrm{~min}$. After pipetting $0.5 \mathrm{ml}$ of ALA solution into the sample tube and $0.5 \mathrm{ml}$ of distilled water into the blank tube, incubate both tubes for $60 \mathrm{~min}$ at $37^{\circ} \mathrm{C}$. Stop the reaction by adding $1 \mathrm{ml}$ of TCA reagent to each test tube 


\section{FLUOROMETRY FOR ALA-D DETERMINATION}

and shake well. Centrifuge the tubes for $5 \mathrm{~min}$ at $3.000 \mathrm{rpm}$. Mix $1 \mathrm{ml}$ of the clear supernatant with $3 \mathrm{ml}$ of Ehrlich's reagent. After $10 \mathrm{~min}$, measure the absorbance agains each corresponding blank at $555 \mathrm{~nm}$. The ALA-D activity was expressed as nanomoles of porphobilinogen formed per hour per milliliter of erythrocytes (RBC). The molar absorbancy of $6.4 \times 10^{4} \mathrm{liter} / \mathrm{mol} \mathrm{cm}$ was used for the porphobilinogen-Ehrlich's reagent complex.

\section{Fluorometric method}

The enzyme assay was carried out according to the slight modification of Weissberg, et al. ${ }^{2)}$ procedure. In each of two test tubes (sample and blank), $0.05 \mathrm{ml}$ of whole blood was well hemolyzed in $1.45 \mathrm{ml}$ of distilled water, and then $0.5 \mathrm{ml}$ of phosphate buffer was added. The tubes were placed in a constant-temperature water bath at $37^{\circ} \mathrm{C}$ for $5 \mathrm{~min}$. After pipetting $0.5 \mathrm{ml}$ of ALA solution into the sample tube and equal volume of distilled water into the blank tube, both tubes were incubated for $60 \mathrm{~min}$ at $37^{\circ} \mathrm{C}$. The enzyme reaction was stopped by adding $1 \mathrm{ml}$ of TCA to them and by shaking well, after rapid cooling of the incubation tubes in a melting ice bath. After centrifuging for $5 \mathrm{~min}$ at $3,000 \mathrm{rpm}, 1 \mathrm{ml}$ of the supernatent was pipetted into another test tube. The operation of the rapid cooling yields a clear supernatent after centrifugation. The tube was heated for $15 \mathrm{~min}$ in a boiling water bath (at $100^{\circ} \mathrm{C}$ ) to convert porphobilinogen to uroporphyrin. After cooling, to the tubes was added $2 \mathrm{ml}$ of distilled water and mixed. The fluorescene for the sample, blank and coproporphyrin standard was measured using a Shimazu Model RF-502 corrected, recording spectrofluorophotometer (excitation wavelength, $408 \mathrm{~nm}$; emission wavelength, $598 \mathrm{~nm}$ ). The spectral band width was set at $10 \mathrm{~nm}$ (excitation) and $7 \mathrm{~nm}$ (emission). The fluorescence intensity of the uroporphyrin prepared from porphobilinogen forming during incubation remains unchanged for at least 2-3 hours at room temperature.

The ALA-D activity was expressed as nanomoles of uroporphyrin formed per hour per milliliter of erythrocytes (RBC) and it was calculated according to the following formula :

$$
\frac{\mathrm{Fs}-\mathrm{Fb}}{\mathrm{Fc}} \times 1.11 \times \frac{1000}{654} \times 0.1 \times \frac{3.5 \times 3}{0.05} \times \frac{100}{\mathrm{Ht}}=\frac{\mathrm{Fs}-\mathrm{Fb}}{\mathrm{Fc}} \times \frac{100}{\mathrm{Ht}} \times 35.64
$$

where $\mathrm{Fs}=$ fluorescence of sample, $\mathrm{Fb}=$ fluorescence of blank (for normal blood, it was practically negligible), $\mathrm{Fc}=$ fluorescence of coproporphyrin standard $(0.1 \mu \mathrm{g} / \mathrm{m} l$ in $1.5 \mathrm{~N} \mathrm{HCl})$, $1.11=$ conversion factor of fluorescence of coproporphyrin I into fluorescence of uroporphyrin (it was estimated from the data of Sassa, et al. ${ }^{13)}$ ), 654=mol. wt. of coproporphyrin, $\mathrm{Ht}=$ hematocrit (\%).

\section{REsults AND Discussion}

The data concerning uroporphyrin formation from porphobilinogen which is excreted in the urine of a patient with acute porphyria were first introduced by Westall ${ }^{14}$. He 


\section{K. TOMOKUNI}

reported that the uroporphyrin is obtained by boiling the acidic solution of porphobilinogen. The fluorometric method for determination of erythrocyte ALA-D activity in the present paper is an application of this principle.

The comparison of fluorescence spectrum for the coproporphyrin standard with that for the uroporphyrin formed from porphobilinogen is shown in Fig. 1. The pattern for

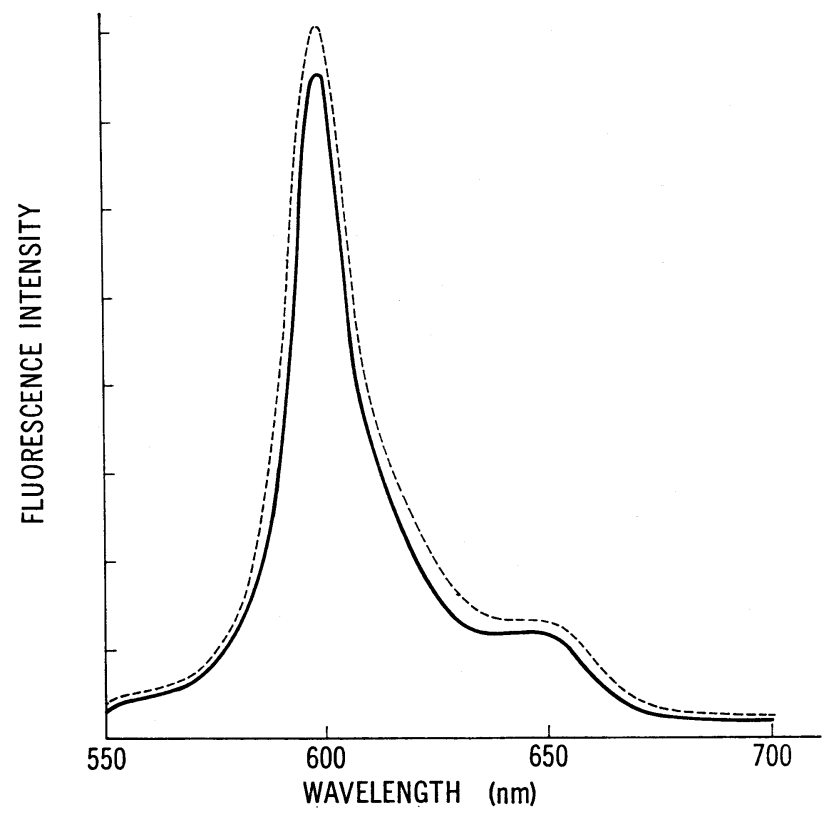

Fig. 1. Fluorescence spectrum of coproporphyrin standard (---) and uroporphyrin $(-)$ formed from porphobilinogen.

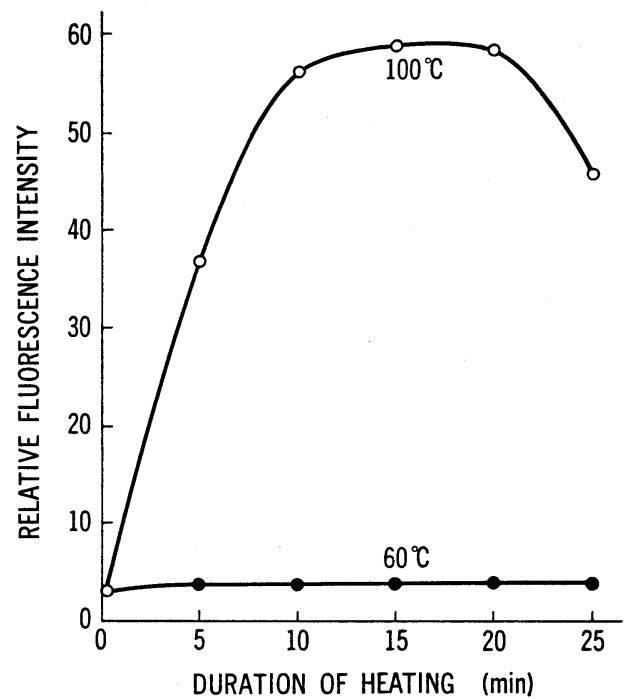

Fig. 2. Effect of heating time and temperature on the uroporphyrin formation from porphobilinogen. Each point shows the mean value by duplicate analyses. 


\section{FLUOROMETRY FOR ALA-D DETERMINATION}

fluorescence spectrum obtained by scanning through the range $550-700 \mathrm{~nm}$ was identical under the present fluorometric conditions and they showed a maximum at $598 \mathrm{~nm}$.

The relationship between the relative fluorescence intensity of uroporphyrin formed from porphobilinogen and the duration of heating is shown in Fig. 2. Under the condition that the supernatant solution containing porphobilinogen after incubation is heated at $60^{\circ} \mathrm{C}$, the conversion of porphobilinogen to uroporphyrin was seldom detected during $25 \mathrm{~min}$. The optimum conversion to uroporphyrin was obtained by heating the acidic solution of porphobilinogen for 15 to $20 \mathrm{~min}$ in the boiling water bath $\left(100^{\circ} \mathrm{C}\right)$. According to the paper of Chakrabarti, et al. ${ }^{12)}$, the yield of uroporphyrin from porphobilinogen was $50-60 \%$. However, I did not try to calculate it under my experimental condition.

The relationship between the relative fluorescence intensity for ALA-D activity and the volume of whole blood used is shown in Fig. 3. The activity was directly proportional to the amount of whole blood present in the incubation mixture.

In Fig. 4, the activity value of erythrocyte ALA-D obtained by the fluorometric method for determing uroporphyrin was compared with that obtained by the colorimetric method for determing porphobilinogen. The correlation between the results obtained by the two methods was highly significant $(\mathrm{P}<0.001)$, with a correlation coefficient of 0.9484 . The ALA-D activity obtained from 60 blood specimens by simultaneous measurement averaged $111 \pm 43(\mathrm{SD}) \mathrm{n} \mathrm{mol}$ of uroporphyrin $/ \mathrm{hr} / \mathrm{ml}$ of erythrocytes by the fluorometric method and $797 \pm 255$ (SD) $\mathrm{nmol}$ of porphobilinogen $/ \mathrm{hr} / \mathrm{ml}$ of erythrocytes by the colorimetric method.

The fluorometric method is sensitive and offers an advantage that it does not require chemical reagents such as p-dimethylaminobenzaldehyde, perchloric acid, and glacial

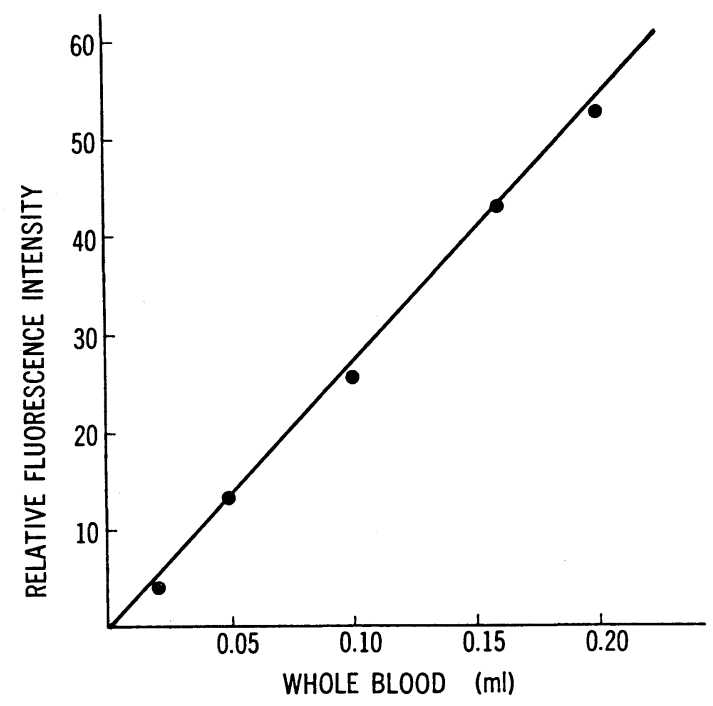

Fig. 3. Relationship between fluorescence intensity and enzyme concentration. Each point shows the mean value by duplicate analyses. 


\section{K. TOMOKUNI}

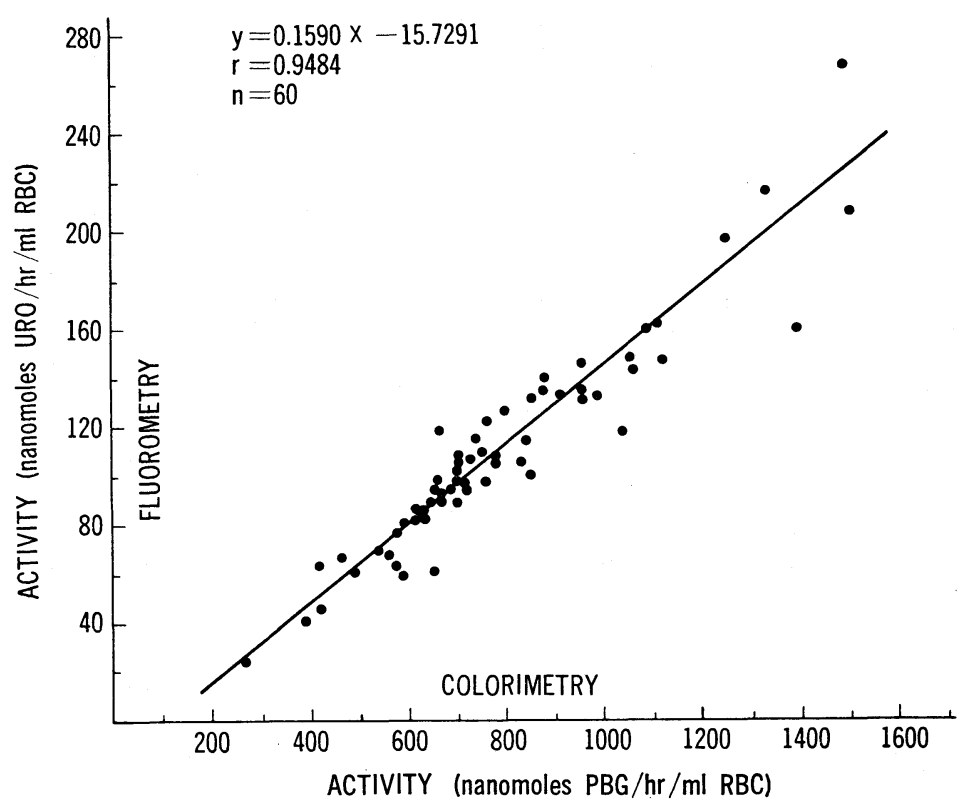

Fig. 4. Comparison of the erythrocyte ALA-D activity, as measured by the fluorometric method and the colorimetric method.

$\mathrm{URO}=$ uroporphyrin, $\mathrm{PBG}=$ porphobilinogen

acetic acid for the preparation of Ehrlich's reagent. In addition, comparing the proposed fluorometric method with the colorimetric method of Weissberg, et al. ${ }^{2)}$, in both methods $0.05 \mathrm{ml}$ of whole blood is used, the former was much more sensitive than the latter, Therefore, it can be demonstrated that the fluorometric method is applicable even for the ALA-D measurement of the highly lead-exposed bloods which exceed the limit of sensitivity of the ALA-D by the Weissberg, et al. ${ }^{2)}$ method.

\section{REFERENCES}

1) Hernberg, S., Nikkanen, J., Mellin, G. and Lilius, H. (1970). Arch. Environ. Health, 21, 140.

2) Weissberg, J. B., Lipschutz, F. and Oski, F. A. (1971). New Engl. J. Med., 284, 565.

3) Nikkanen, J., Hernberg, S. and Tola, S. (1972). Work Environ. Health, 9, 46.

4) Tomokuni, K. (1974). Arch. Environ. Health, 29, 274.

5) Bonsignore, D., Calissano, P. and Cartasegna, C. (1965). Med. Lav., 56, 199.

6) Wada, O. Yano, Y., Kurashina, S., et al. (1970). Asian Med. J., 13, 581.

7) Burch, H. B. and Siegel, A. L. (1971). Clin. Chem., 17, 1038.

8) Berlin, A. and Schaller, K. H. (1974). Z. Klin. Chem. Klin. Biochem., 12, 389.

9) Gibson, K. D., Neuberger, A. and Scott, J. J. (1955). Biochem. J., 61, 618.

10) Granick, S. and Mauzerall, D. (1958). J. Biol. Chem., 232, 1119.

11) Tomokuni, K. (1974). Clin. Chem., 20, 1287.

12) Chakrabarti, S. K., Brodeur, J. and Tardif, R. (1975). Clin. Chem., 21, 1783.

13) Sassa, S., Granick, J. L., Granick, S., et al. (1973). Biochem. Med., 8, 135.

14) Westall, R. G. (1952). Nature, 170, 614. 